\title{
Determinative factors in surgical planning of eyebrow cosmetic and reconstructive surgery
}

\author{
This article was published in the following Dove Press journal: \\ Clinical Ophthalmology \\ 24 July 2017 \\ Number of times this article has been viewed
}

\author{
Mohammad Taher Rajabi \\ Ali Makateb \\ Narges Hassanpoor \\ Seyedeh Simindokht Hosseini \\ Fatameh Bazvand \\ Syed Ziaeddin Tabatabaie \\ Mohammad Bagher Rajabi \\ Department of Ophthalmology, Eye \\ Research Center, Farabi Eye Hospital, \\ Tehran, Iran
}

Purpose: The purpose of this study was to identify the different factors that an oculoplastic surgeon should consider while practicing cosmetic or reconstructive eyebrow surgery in order to have the final patient's satisfaction.

Subjects and methods: In an observational case series study, five photographs were taken from each of 60 females to show ideal eyebrow positioning with fingers. Eyebrow landmarks, including tarsal plate show (TPS) and eyebrow height, were measured in the ideal position. Brow apex position and brow apex angle were evaluated in the desired position of eyebrow.

Results: The mean desired apex angle of eyebrow was measured as $135 \pm 9 \mathrm{~mm}$. In all, $48.33 \%$ of our subjects preferred a wider brow angle, $28.33 \%$ a narrower one, and $23.33 \%$ a brow angle without any change. The location of brow peak was transferred to the lateral canthus in the desired position. The ideal brow peak in the lateral canthus and between lateral canthus and lateral limbus was assigned to $33.3 \%$ and $66.6 \%$ of cases, respectively. The desired eyebrow apex angle in two age groups of our subjects ( $>40$ years and $\leq 40$ years) was not statistically different.

Conclusion: Landmarks of the eyebrow and its desired position are somehow different between different studies, which may be explained by the variation in race, gender, culture, and age. As there is not any uniform rule in planning of cosmetic surgeries of eyebrow, oculoplastic surgeons should consider the difference in culture, race, age, and desire of the patients and have their surgical plans for every individual patient distinctively.

Keywords: eyebrow, tarsal plate show, brow apex angle, desired brow position, brow height

\section{Eyebrow position importance}

The eyebrow shape and position have a great role and influence on the cosmetic aspects of facial appearance. The appearance of the eyebrows is invested with an emotional, expressive, and psychological significance that makes them one of the most prominent features of the face. Studies have shown that one instantaneously and subconsciously makes a determination of another person's mood just by glancing at the position and appearance of eyebrows. ${ }^{1}$ In spite of several regulations that are created as ideal proportions of face and are used as a guide, the esthetic operations remain challenging. ${ }^{1}$ Various parameters in the orbital region determine the facial appearance, including palpebral fissure height, eyelid crease, relation between eyebrow and orbital ridge, and location of brow apex. These parameters vary greatly between different races and culture. Age and gender can also affect and determine the ideal status of eyebrows. The features of face are the milestones of desired shape of eyebrow. ${ }^{2-5}$ In this study, we have evaluated the ideal amount of brow angle in 60 normal females, which can provide a guide for oculoplastic surgeons.
Correspondence: Narges Hassanpoor Department of Ophthalmology, Eye Research Center, Farabi Eye Hospital, Qazvin Square, Tehran I3366I635I, Iran $\mathrm{Tel}+982155421006$ Fax +98 2I 554I6I34 Email nargeshassanpoor@gmail.com (c) (i) (5) 2017 Rajabi et al. This work is published and licensed by Dove Medical Press Limited. The full terms of this license are available at https://www.dovepress.com/terms.php (c) ${ }_{\mathrm{BY}} \mathrm{NC}$ and incorporate the Creative Commons Attribution - Non Commercial (unported, v3.0) License (http://creativecommons.org/licenses/by-nc/3.0/). By accessing the work you hereby accept the Terms. Non-commercial uses of the work are permitted without any further permission from Dove Medical Press Limited, provided the work is properly attributed. For permission for commercial use of this work, please see paragraphs 4.2 and 5 of our Terms (https://www.dovepress.com/terms.php). 


\section{Subjects and methods}

A total of 60 healthy females with the age ranging between 22 and 53 years without any previous history of plucked, removed, or tattooed eyebrows; facial surgery; facial trauma; and significant psychiatric problems who agreed to enroll in the research were studied. After complete explanation, oral informed consent was obtained. This study has been done under the observation of and approval by the ethics committee of Farabi Eye Hospital based on principles of the Declaration of Helsinki. Based on the committee policy for only observational studies, oral informed consent could be sufficient. The person in the images provided written consent for the images to be published. First, five photographs were taken by a Sony digital camera to show their ideal eyebrow positioning with fingers. The amount of tarsal plate show (TPS) was measured in three points, including medial canthus, mid pupil, and lateral canthus. The amount of brow fat span (BFS) in mid pupil, lateral limbus, and lateral canthus was calculated from the photographs (Figure 1). The height of eyebrow was calculated by the height between top of eyebrow and the line passing horizontally from the inferior boundary of medial portion of the eyebrow (Figure 2). The location and angle of eyebrow apex were considered. The brow apex angle was supposed as the angle between the medial portion of brow (usually the medial two-thirds) and brow tail (the lateral one-third). All of these variables were reported in millimeters (mm). All parameters have been measured by one examiner.

In Figure 3, the desired eyebrow position is depicted by one of the subject's own finger in the mirror. The analysis of this investigation was done by SPSS version 19. The data were reported by mean $\pm \mathrm{SD}$. The percentage of the desired brow angle is reported.

\section{Results}

Our cases included 60 normal females with a mean age of $33.63 \pm 9.05$ years. The amounts of TPS and BFS are shown in Table 1.

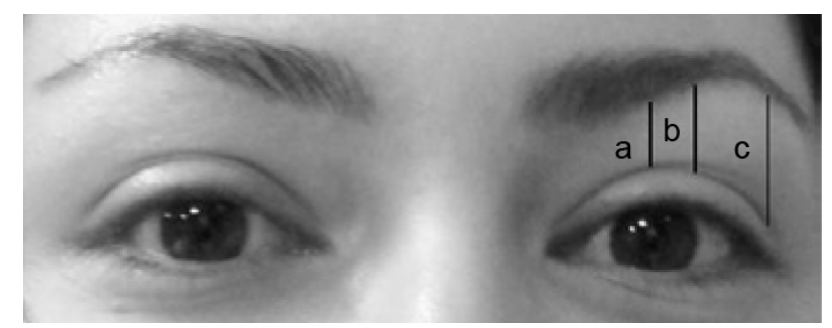

Figure I Measuring amount of BFS in mid pupil (a), lateral limbus (b), and lateral canthus (c).

Abbreviation: BFS, brow fat span.

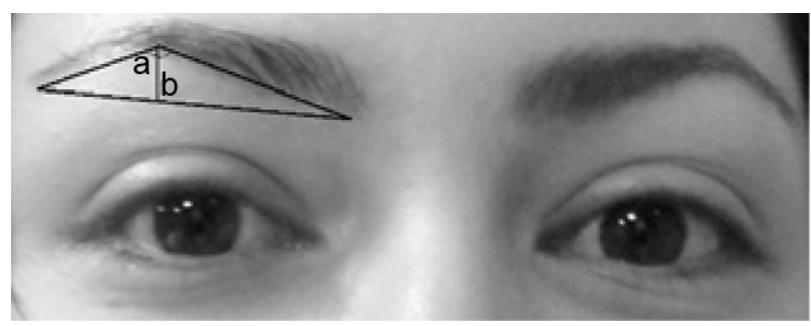

Figure 2 Calculation of the brow angle (a) and brow height (b).

The most common location of eyebrow peak was between lateral limbus and lateral canthus in $58.3 \%$ (35 cases) of subjects, followed by the lateral canthus ( $28.3 \%$ or 17 cases) and the lateral limbus ( $10 \%$ or six cases). There was no detectable eyebrow peak in two patients $(3.3 \%)$.

The mean height of eyebrow was $7.51 \pm 1.85 \mathrm{~mm}$, ranging from 4 to $13 \mathrm{~mm}$. The mean desired apex angle of eyebrow was measured as $135 \pm 9 \mathrm{~mm}$. In all, $48.33 \%$ of our subjects preferred a wider brow angle, $28.33 \%$ a narrower one, and $23.33 \%$ a brow angle without any change, but the location of brow peak was transferred to the lateral canthus in the desired position. Ideal brow peak in the lateral canthus and between lateral canthus and lateral limbus was assigned to $33.3 \%$ and $66.6 \%$ of cases, respectively. The desired eyebrow apex angle was estimated and compared between two age groups of our subjects, and the results are shown in Table 2. There was no statistically significant difference between these age groups $(P<0.05)$.

Cosmetic surgery was not performed for subjects after this study.

\section{Discussion}

Different variables affect the cosmetic aspects of eyebrows and consequently the cosmetic aspects of face, which comprise features of brow itself, location and amount of brow apex angle, quantity of BFS, relationship between brow and supraorbital ridge, and TPS. Eyebrow position

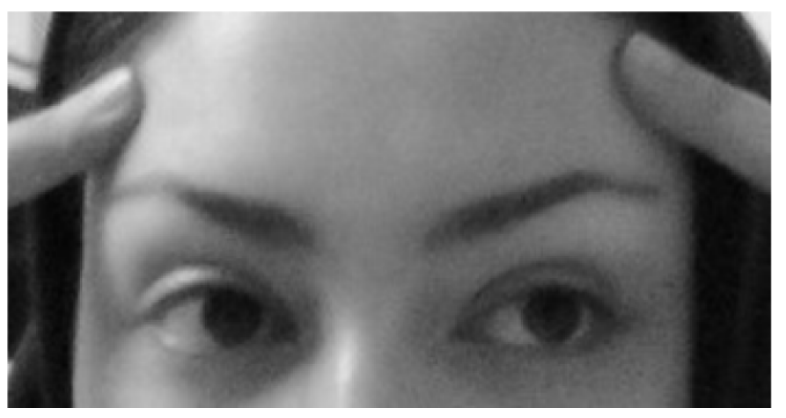

Figure 3 Desired eyebrow position is depicted by one of the subject's own finger in the mirror. 
Table I The amount of TPS and BFS

\begin{tabular}{llllll}
\hline Variable & $\begin{array}{l}\text { TPS - medial } \\
\text { canthus }\end{array}$ & $\begin{array}{l}\text { TPS - mid } \\
\text { pupil }\end{array}$ & $\begin{array}{l}\text { TPS - lateral } \\
\text { canthus }\end{array}$ & $\begin{array}{l}\text { BFS - mid } \\
\text { pupil }\end{array}$ & $\begin{array}{l}\text { BFS - lateral } \\
\text { limbus }\end{array}$ \\
\hline Mean $\pm S D$ & $3.48 \pm I .01$ & $3.7 I \pm I .64$ & $3.66 \pm I .14$ & $9.40 \pm 3.12$ & $11.83 \pm 3.24$ \\
\hline
\end{tabular}

Abbreviations: TPS, tarsal plate show; BFS, brow fat span; SD, standard deviation.

and characteristics are important in sexual dimorphism and ethnic features of the face. ${ }^{6}$

One of the parameters is the location of eyebrow apex that has been investigated in different studies. The various positions suggested were at the lateral canthus and over the lateral limbus by Cook et al ${ }^{7}$ and Kunjur et al, ${ }^{8}$ respectively. Another implication is that brow apex should be located at the intersection of middle and lateral thirds of upper eyelid. ${ }^{9}$ In the study by Kunjur et al, ${ }^{8}$ the apex of brow was positioned among the lateral limbus and lateral canthus in all cases with the exception of Indian men. In our study, the most frequent brow peak was located between lateral limbus and lateral canthus too. However in the remaining, the peak was situated at lateral limbus or lateral canthus. These differences may be explained by variation in race, gender, and age. In the investigation of Biller and $\mathrm{Kim},{ }^{10}$ satisfying brow peak was located on the lateral limbus or middle of lateral limbus and lateral canthus. Sclafani and Jung ${ }^{11}$ showed that the desired brow peak was located on the lateral canthus, lateral limbus or middle of lateral canthus, and lateral limbus based on the age and race of subjects. Pham et $\mathrm{al}^{12}$ described deep temporal fusion line as a new predictor of ideal brow peak in patients undergoing endoscopic brow lift procedures as the lateral limbus and medial two-thirds and lateral one-third junction may be a good indicator of brow peak in females, but it is not as equally useful as the deep temporal fusion line in the prediction of brow peak position in males and females. Our subjects preferred lateral canthus and places between lateral limbus and lateral canthus as the desired position for brow peak.

The location of brow under the supra orbital ridge in the medial part ${ }^{9}$ and $1 \mathrm{~cm}$ on top of supra orbital ridge ${ }^{13}$ was suggested as a desired position in different studies.

The differences between two genders were considered in these variables in both anatomical status and ideal status. ${ }^{12,14,15}$

Table 2 Desired eyebrow apex angle compared between two age groups

\begin{tabular}{llllll}
\hline Variable & $\begin{array}{l}\text { Age } \\
\text { (years) }\end{array}$ & n & Mean & SD & $\begin{array}{l}\text { Standard error } \\
\text { of the mean }\end{array}$ \\
\hline Eyebrow angle & $>40$ & 15 & 134.66 & 8.12 & 2.09 \\
& $\leq 40$ & 45 & 135.44 & 9.22 & 1.37 \\
\hline
\end{tabular}

Abbreviation: SD, standard deviation.
We also measured the distance between the upper border of lid crease and lower edge of brow in three points, including mid pupil, lateral limbus, and lateral canthus. The results were between 3 and $18 \mathrm{~mm}, 4$ and $19 \mathrm{~mm}$, and 12 and $30 \mathrm{~mm}$, respectively. Kunjur et $\mathrm{al}^{8}$ established the amount of $7-12 \mathrm{~mm}$; however, the amount of $15-16 \mathrm{~mm}$ was suggested for the ideal position. ${ }^{16,17}$

We measured the brow height in our subjects, and the result was $4-13 \mathrm{~mm}$; nevertheless, a number of 13 was achieved in the other survey. ${ }^{11}$

In other studies, the concept of ideal brow position and shape was greatly affected by age. ${ }^{11,18,19}$ Feser et al ${ }^{18}$ showed in their study that subjects younger than 30 years prefer eyebrows with lower positions and also ruled out arch, and it was exactly the opposite in groups of subjects older than 50 years. However in our study, there was no significant difference in the brow position preference between two age groups of our subjects younger and older than 40 years (Table 2). In the study by Kim et al, ${ }^{20}$ there was not any significant difference in borrow archetype preference in different age groups, different educational levels, and single versus married women. As a limitation, we did not study our subjects' desired eyebrow position based on their educational level and marital status.

The most significant result in our study that was never mentioned in other studies or it was considered without any change ${ }^{11,19}$ was the wider brow apex angle preference. The brow apex angle (the angle between the medial portion of brow and brow tail) was significantly changed in the desired position of this study and became wider. In fact, the majority of our subjects believed in eyebrows with a wider apex angle as an ideal pattern, even more eminent than the shape and location of the apex of the eyebrow itself.

One of the major drawbacks of this study would be its population study, which comprises only female subjects. However, there is a fact that the majority of cases looking for cosmetic and reconstructive surgeries of eyebrows in our population study are females; thus, assessment of their desired eyebrow position would be favorable and useful information for planning of cosmetic and reconstructive surgery of eyebrows in our country. However, another drawback of this study would be its fairly small population of study. 
The oculoplastic surgery for restoring ideal appearance is challenging and follows the special rules in facial proportions that are various in different races. ${ }^{15,20}$ By gathering miscellaneous information on this topic and consideration of the difference in culture, race, and desire of the patients, oculoplastic surgeons all around the world should have their surgical plans for every individual patient distinctively. In addition to these rules, the discernment of subject should be attended for obtaining arbitrary results.

\section{Acknowledgments}

This paper content was presented as a poster at the American Academy of Ophthalmology Annual Meeting, November 2013, New Orleans, USA. It has also been presented orally in "IV Annual Congress of Iranian Research Association for Vision and Ophthalmology (IRAVO), February 2014, Tehran, Iran" and "XXII Annual Congress of the Iranian Society of Ophthalmology, October 2013, Tehran, Iran. ${ }^{21}$ This manuscript has not been published or submitted for publication elsewhere.

\section{Disclosure}

The authors report no conflicts of interest in this work.

\section{References}

1. Naif-de-Andrade NT, Hochman B, Naif-de-Andrade CZ, Ferreira LM. Computerized photogrammetry used to calculate the brow position index. Aesthetic Plast Surg. 2012;36(5):1047-1051.

2. Yalçınkaya E, Cingi C, Söken H, Ulusoy S, Muluk NB. Aesthetic analysis of the ideal eyebrow shape and position. Eur Arch Otorhinolaryngol. 2016;273(2):305-310.

3. Liew $\mathrm{S}$. Ethnic and gender considerations in the use of facial injectables: Asian patients. Plast Reconstr Surg. 2015;136(5 suppl):22S-27S.

4. Papageorgiou KI, Ang M, Chang SH, Kohn J, Martinez S, Goldberg RA. Aesthetic considerations in upper eyelid retraction surgery. Ophthal Plast Reconstr Surg. 2012;28(6):419-423.
5. Zoumalan CI, Roostaeian J. Simplifying blepharoplasty. Plast Reconstr Surg. 2016;137(1):196e-213e.

6. Packiriswamy V, Kumar P, Bashour M. Photogrammetric analysis of eyebrow and upper eyelid dimensions in South Indians and Malaysian South Indians. Aesthet Surg J. 2013;33(7):975-982.

7. Cook TA, Brownrigg P, Wang TD, Quatela VC. The versatile midforehead browlift. Arch Otolaryngol Head Neck Surg. 1989;115(2): $163-168$.

8. Kunjur J, Sabesan T, Ilankovan V. Anthropometric analysis of eyebrows and eyelids: an inter-racial study. Br J Oral Maxillofac Surg. 2005; 44(2):89-93.

9. Whitaker LA, Morales L, Farkas LG. Aesthetic surgery of the supraorbital ridge and forehead structures. Plast Reconstr Surg. 1986;78(1): 23-32.

10. Biller JA, Kim DW. A contemporary assessment of facial aesthetic preferences. Arch Facial Plast Surg. 2009;11(2):91-97.

11. Sclafani AP, Jung M. Desired position, shape, and dynamic range of the normal adult eyebrow. Arch Facial Plast Surg. 2010;12(2):123-127.

12. Pham S, Wilhelmi B, Mowlavi A. Eyebrow peak position redefined. Aesthet Surg J. 2010;30(3):297-300.

13. Ellenbogen R. Transcoronal eyebrow lift with concomitant upper blepharoplasty. Plast Reconstr Surg. 1983;71(4):490-499.

14. Cartwright MJ, Kurumety UR, Nelson CC, Frueh BR, Musch DC. Measurements of upper eyelid and eyebrow dimensions in healthy white individuals. Am J Ophthalmol. 1994;117(2):231-234.

15. Price KM, Gupta PK, Woodward JA, Stinnett SS, Murchison AP. Eyebrow and eyelid dimensions: an anthropometric analysis of African Americans and Caucasians. Plast Reconstr Surg. 2009;124(2):615-623.

16. Connell BF, Lambros VS, Neurohr GH. The forehead lift: technique to avoid complications and produce optimal results. Aesthetic Plast Surg. 1989;13(4):217-237.

17. McKinney P, Mossie RD, Zukowski ML. Criteria for the forehead lift. Aesthetic Plast Surg. 1991;15(2):141-147.

18. Feser DK, Grundl M, Eisemann-Klein M, Prantl L. Attractiveness of eyebrow position and shape in females depends on the age of the beholder. Aesthetic Plast Surg. 2007;31(2):154-160.

19. Matai O, Lavezzo MM, Schellini SA, Padovani Carlos RP, Padovani R. Evaluation of eyebrow position using angular measures. Arq Bras Oftalmol. 2007;70(1):41-44.

20. Kim SK, Cha SH, Hwang K, Hwang SW, Kim YS. Brow archetype preferred by Korean women. J Craniofac Surg. 2014;25(4):1207-1211.

21. Rajabi Mt, Makateb A. Free papers session in orbit and cosmetic surgery. Presented at: 22nd Iranian Society of Ophthalmology congress; October; 2013; Tehran, Iran.

\section{Clinical Ophthalmology}

\section{Publish your work in this journal}

Clinical Ophthalmology is an international, peer-reviewed journal covering all subspecialties within ophthalmology. Key topics include: Optometry; Visual science; Pharmacology and drug therapy in eye diseases; Basic Sciences; Primary and Secondary eye care; Patient Safety and Quality of Care Improvements. This journal is indexed on Submit your manuscript here: http://www.dovepress.com/clinical-ophthalmology-journal

\section{Dovepress}

PubMed Central and CAS, and is the official journal of The Society of Clinical Ophthalmology (SCO). The manuscript management system is completely online and includes a very quick and fair peer-review system, which is all easy to use. Visit http://www.dovepress.com/ testimonials.php to read real quotes from published authors. 